\title{
Bio-based thermosetting resins composed of cardanol novolac and bismaleimide
}

\author{
Mitsuhiro Shibata, Yusuke Itakura and Hironori Watanabe \\ Cardanol novolac (CDN) was synthesized by the reaction of cardanol (CD) and paraformaldehyde in the presence of oxalic acid. \\ The prepolymerized compounds of $\mathrm{CD} / 4,4^{\prime}$-bismaleimidediphenylmethane (BMI) and $\mathrm{CDN} / \mathrm{BMI}$ with $\mathrm{CD} / \mathrm{maleimide}$ unit ratios \\ $1 / 2,1 / 4$ and $1 / 6$ at $200^{\circ} \mathrm{C}$ were finally compression-molded at $250^{\circ} \mathrm{C}$ for $5 \mathrm{~h}$ to produce cured CD/BMI (cCD/BMI) and cured \\ CDN/BMI (CCDN/BMI) resins. Although the proton nuclear magnetic resonance $\left({ }^{1} \mathrm{H}-\mathrm{NMR}\right)$ and Fourier transform infrared \\ spectroscopy (FTIR) analyses of the model reaction product of CD and $\mathrm{N}$-phenylmaleimide (PMI) at $200^{\circ} \mathrm{C}$ for $8 \mathrm{~h}$ suggested \\ the occurrence of the ene reaction and subsequent Diels-Alder reaction, the FTIR analysis of cCD/BMI and cCDN/BMI \\ suggested the occurrence of the ene reaction and addition copolymerization. The $\mathrm{CCD} / \mathrm{BMI}$ and $\mathrm{cCDN} / \mathrm{BMI}$ with CD/maleimide \\ ratio lower than $1 / 2$ did not show glass transition until $300^{\circ} \mathrm{C}$ and had a $5 \%$ weight loss temperature higher than $450{ }^{\circ} \mathrm{C}$. \\ The $\mathrm{CCD} / \mathrm{BMI}$ and $\mathrm{CCDN} / \mathrm{BMI}$ with $\mathrm{CD} /$ maleimide ratio $1 / 4$ showed the most balanced flexural properties (flexural strength \\ 60-80 MPa, flexural modulus $2.0-2.5 \mathrm{GPa}$ ).
}

Polymer Journal (2013) 45, 758-765; doi:10.1038/pj.2012.195; published online 21 November 2012

Keywords: bismaleimide; cardanol; cardanol novolac; Diels-Alder reaction; ene reaction; renewable resources; thermosets

\section{INTRODUCTION}

In recent years, renewable resources-derived polymers (bio-based polymers) are attracting a great deal of attention because of the advantages of these polymers, such as conservation of limited petroleum resources, possible biodegradability and the control of carbon dioxide emissions that lead to global warming. ${ }^{1-4}$ Most recently, much focus is being placed on bio-based thermosetting resins, such as epoxy resins, phenol resins, unsaturated polyester resins and their composites, because these materials are hard to be recycled owing to the infusible and insoluble properties. ${ }^{5-9}$ Petroleum-based thermosetting bismaleimide resins are used as the matrix resins for multilayer printed circuit boards and advanced composite materials in the aerospace industry. ${ }^{10-15}$ For example, a commercial thermosetting bismaleimide resin, Matrimid 5292 (Ciba Geigy, Basel, Switzerland), based on 2,2'-diallybisphenol A (DABA)/ $4,4^{\prime}$-bismaleimidediphenylmethane (BMI) is one of the leading matrix resins in carbon fiber composites for advanced aerospace application. ${ }^{13}$ The Fourier transform infrared spectroscopy (FTIR) analysis of the cured DABA/BMI resin has shown that a stepwise ene reaction and subsequent chain polymerization in addition to an etherification reaction occur for DABA/BMI. ${ }^{14,15}$ We had already reported the thermal and mechanical properties of the BMI cured with drying oil such as dehydrated castor oil and tung oil. ${ }^{16,17}$ Cardanol (CD) is a promising bio-based feedstock, which is obtained from anacardic acid, the main component of cashew nutshell liquid, a by-product of cashew nut processing. $\mathrm{CD}$ is a phenol meta-substituted with a long unsaturated hydrocarbon chain $\left(\mathrm{C}_{15} \mathrm{H}_{31-2 x}: x=\right.$ degree of unsaturation; $0-3$, average $\left.x \cong 2.1\right),{ }^{18,19}$ which is expected to undergo the ene reaction and subsequent Diels-Alder reaction with BMI (Figure 1). There have been many reports in the literature on the utilization of CD to phenol resins ${ }^{20-22}$ and epoxy resins. ${ }^{22-25}$ However, there are only a few reports on the application of $\mathrm{CD}$ by use of the reactivity of the unsaturated hydrocarbon chain. ${ }^{26}$ To the best of our knowledge, the curing reaction of $\mathrm{CD}$ and maleimide has not yet been reported. Herein, the thermal and mechanical properties of the $\mathrm{CD}$ and $\mathrm{CD}$ novolac $(\mathrm{CDN})$ cured with BMI are investigated. The curing mechanism is elucidated by the proton nuclear magnetic resonance $\left({ }^{1} \mathrm{H}-\mathrm{NMR}\right)$ and FTIR analyses of the model reaction products of $\mathrm{CD}$ and $N$-phenylmaleimide (PMI) and the FTIR analysis of the cured CD/ $\mathrm{BMI}(\mathrm{cCD} / \mathrm{BMI})$ and cured $\mathrm{CDN} / \mathrm{BMI}$ (cCDN/BMI) resins.

\section{EXPERIMENTAL PROCEDURE}

Materials

CD was kindly supplied from Cashew Company (Saitama, Japan). Paraformaldehyde and oxalic acid dihydrate were purchased from Wako Pure Chemical Industries (Osaka, Japan) and Kanto Chemical (Tokyo, Japan), respectively. BMI was purchased from Tokyo Kasei Kogyo (Tokyo, Japan). All the commercially available reagents were used without further purification. 
<smiles>Oc1cccc(P)c1</smiles>

$\mathrm{CD}$

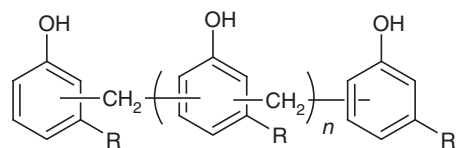

CDN
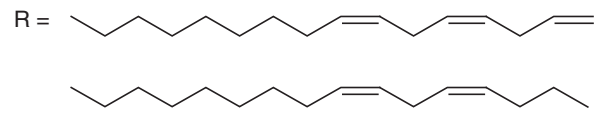

(N)

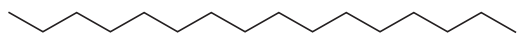

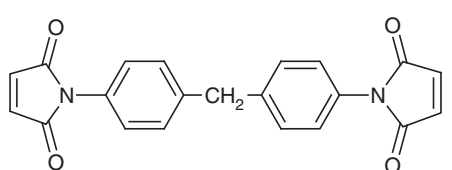

BMI

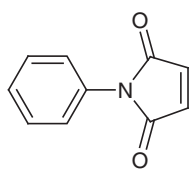

PMI
Figure 1 Structures of cardanol (CD), cardanol novolac (CDN), $\mathrm{N}$-phenylmaleimide (PMI) and 4,4'-bismaleimidediphenylmethane (BMI).

\section{Synthesis of CDN}

The molecular weight of $\mathrm{CD}$ (300.2), calculated from the chemical formula $\mathrm{C}_{21} \mathrm{H}_{36-2 x} \mathrm{O}$ (average degree of unsaturation $x=2.14$ determined by ${ }^{1} \mathrm{H}-\mathrm{NMR}$ method) was used for the calculation of the feed amount of $\mathrm{CD}$. A mixture of $\mathrm{CD} 30.0 \mathrm{~g}(0.100 \mathrm{~mol})$, paraformaldehyde $1.82 \mathrm{~g}\left(\mathrm{CH}_{2} \mathrm{O}\right.$ unit: $\left.0.0606 \mathrm{~mol}\right)$ and oxalic acid dehydrate $0.900 \mathrm{~g}(7.13 \mathrm{mmol})$ was reacted at $120^{\circ} \mathrm{C}$ for $6 \mathrm{~h}$. After chloroform $(300 \mathrm{ml})$ was added to the reaction mixture, the solution was washed with water, and dried with sodium sulfate. The chloroform solution was filtered, and then concentrated in vacuo at $200{ }^{\circ} \mathrm{C}$ to produce $\mathrm{CDN} 27.3 \mathrm{~g}$ in $89 \%$ yield.

\section{Preparation of the cured materials of $\mathrm{CD}$ and $\mathrm{BMI}$}

A mixture of CD $13.7 \mathrm{~g}(45.6 \mathrm{mmol})$ and BMI $16.3 \mathrm{~g}$ (maleimide unit: $91.2 \mathrm{mmol}$ ) was stirred at $200^{\circ} \mathrm{C}$ for ca. $4 \mathrm{~h}$ to produce a gelatinous material. The obtained compound was compression-molded at $200^{\circ} \mathrm{C} / 5 \mathrm{MPa}$ for $1 \mathrm{~h}$, $220^{\circ} \mathrm{C} / 5 \mathrm{MPa}$ for $2 \mathrm{~h}$ and finally $250^{\circ} \mathrm{C} / 5 \mathrm{MPa}$ for $5 \mathrm{~h}$ to produce the cCD/BMI with $\mathrm{CD} /$ maleimide ratio of $1 / 2(\mathrm{cCD} / \mathrm{BMI} 1 / 2)$. In a manner similar to the preparation of $\mathrm{CCD} / \mathrm{BMI} 1 / 2$, the cured resins of $\mathrm{CCD} / \mathrm{BMI}$ with the $\mathrm{CD} /$ maleimide ratios of $1 / 4$ and $1 / 6$ (cCD/BMI $1 / 4$ and $\mathrm{CCD} / \mathrm{BMI} 1 / 6)$ were also prepared.

\section{Preparation of the cured materials of CDN and BMI}

Weight per CD equivalent of CDN (307.4), which was calculated from the number of phenolic units $(p=2.52)$ of $\mathrm{CND}$ evaluated from ${ }^{1} \mathrm{H}-\mathrm{NMR}$ analysis and the molecular weight (675.4) of CDN calculated from the chemical formula $\mathrm{C}_{22 p-1} \mathrm{H}_{(36-2 x) p} \mathrm{O}_{p}$, were used for the calculation of the feed amount of CDN. The parameter, $n$ of CDN shown in Figure 1, is expressed by the equation, $n=p-2$. A mixture of CDN $13.8 \mathrm{~g}$ (CD unit: $44.9 \mathrm{mmol}$ ) and BMI $16.1 \mathrm{~g}$ (maleimide unit: $89.9 \mathrm{mmol}$ ) was stirred at $200^{\circ} \mathrm{C}$ for ca. $0.5 \mathrm{~h}$ to produce a gelatinous material. The compound that was obtained was compression-molded at $200^{\circ} \mathrm{C} / 5 \mathrm{MPa}$ for $1 \mathrm{~h}, 220^{\circ} \mathrm{C} / 5 \mathrm{MPa}$ for $2 \mathrm{~h}$, and finally $250^{\circ} \mathrm{C} / 5 \mathrm{MPa}$ for $5 \mathrm{~h}$ to produce the $\mathrm{cCDN} / \mathrm{BMI}$ with $\mathrm{CD} /$ maleimide ratio of $1 / 2(\mathrm{cCDN} / \mathrm{BMI} 1 / 2)$. In a manner similar to the preparation of cCDN/BMI $1 / 2$, the cured resins of CDN/BMI with $\mathrm{CD} /$ maleimide ratios of $1 / 4$ and $1 / 6$ (cCDN/BMI $1 / 4$ and $\mathrm{CCDN} / \mathrm{BMI} 1 / 6)$ were also prepared.

\section{Model reactions of $\mathrm{CD}$ and $\mathrm{PMI}$}

A mixture of CD $0.928 \mathrm{~g}(3.09 \mathrm{mmol})$ and PMI $1.07 \mathrm{~g}(6.18 \mathrm{mmol})$ was stirred at $200{ }^{\circ} \mathrm{C}$ for $8 \mathrm{~h}$ to give a model reaction product of $\mathrm{CD} / \mathrm{PMI}$ with $\mathrm{CD} /$ maleimide unit ratio of $1 / 2$ (cCD/PMI 1/2). The reaction mixture was used for the ${ }^{1} \mathrm{H}-\mathrm{NMR}$ and FTIR measurements. Similarly, cCD/PMI $1 / 4$ and $\mathrm{CCD} / \mathrm{PMI}$ $1 / 6$ were also prepared.

\section{Measurements}

${ }^{1} \mathrm{H}-\mathrm{NMR}$ spectra were recorded on a Bruker AV-400 (400 MHz) (Madison, WI, USA) using $\mathrm{CDCl}_{3}$ as a solvent. FTIR spectra were measured on an FTIR 8100 spectrometer (Shimadzu, Kyoto, Japan) by the $\mathrm{KBr}$ or attenuated total reflectance methods. The temperature at which $5 \%$ weight loss occurred was measured on a thermogravimetric analyzer TGA7 (Perkin-Elmer Japan, Yokohama, Japan) in a nitrogen atmosphere at a heating rate of $20{ }^{\circ} \mathrm{C} \mathrm{min}-1$. The morphology of the cured resins was observed by field emission-scanning electron microscopy (FE-SEM), using a Hitachi S-4700 machine (Hitachi High-Technologies, Tokyo, Japan). All samples were fractured after immersion in liquid nitrogen for about $10 \mathrm{~min}$. The fracture surfaces were sputter coated with gold to provide enhanced conductivity. Dynamic mechanical analysis of the rectangular plates $\left(40 \times 6 \times 2 \mathrm{~mm}^{3}\right)$ was performed on a Rheolograph Solid instrument (Toyo Seiki, Tokyo, Japan) under air atmosphere with a chuck distance of $20 \mathrm{~mm}$, a frequency of $1 \mathrm{~Hz}$ and a heating rate of $2{ }^{\circ} \mathrm{C} \mathrm{min}{ }^{-1}$, based on ISO 6721-4:1994 (Plastics-Determination of dynamic mechanical properties, Part 4: Tensile vibration-Non-resonance method). Flexural testing of the rectangular specimen $\left(70 \times 10 \times 2 \mathrm{~mm}^{3}\right)$ was performed using an Autograph AG-1 (Shimadzu) based on the standard method for testing the flexural properties of plastics (JIS K7171: 2008 (ISO 178: 2001)). The span length was $30 \mathrm{~mm}$, and the testing speed was $10 \mathrm{~mm} \mathrm{~min}^{-1}$. Five specimens were tested for each set of samples, and the mean values were calculated.

\section{RESULTS AND DISCUSSION}

\section{Characterization of CD and CDN}

Figure $2 \mathrm{a}$ shows the ${ }^{1} \mathrm{H}-\mathrm{NMR}$ spectrum of the used $\mathrm{CD}$ in $\mathrm{CDCl}_{3}$. The ${ }^{1} \mathrm{H}$ signals at $7.21(\mathrm{~m}, 1 \mathrm{H}), 6.83(\mathrm{~m}, 1 \mathrm{H})$ and 6.72 p.p.m. $(\mathrm{m}, 2 \mathrm{H})$ are assigned to the protons, $\mathrm{H}-b, \mathrm{H}-c$ and $\mathrm{H}-a, d$ attached to the benzene ring of $\mathrm{CD}$, respectively. As is shown in Figure $1, \mathrm{CD}$ is known to contain cis, cis, cis-pentadeca-8,11,14-trienyl, cis, cispentadeca-8,11-dienyl, cis-pentadec-8-enyl and pentadecyl moieties, whose fractions are expressed by $f_{3}, f_{2}, f_{1}$ and $f_{0}$, respectively. The ${ }^{1} \mathrm{H}$ signals at 5.10 p.p.m. $(\mathrm{m}, 0.833 \mathrm{H})$ are assigned to $\mathrm{H}-\mathrm{l}$ of the terminal vinyl group of the triene moiety. If it is assumed that the terminal vinyl group is contained only for the triene moiety, the fraction of the triene moiety $\left(f_{3}\right)$ is evaluated to be 0.417 from the equation, $0.833 \mathrm{H}$ / $2 \mathrm{H}$. The ${ }^{1} \mathrm{H}$ signal due to $\mathrm{H}-k$ of the triene moiety was observed at 5.90 p.p.m. (m), which partly overlapped with the phenolic hydroxy proton signal at 5.78 p.p.m. The latter hydroxy proton signal often shifted to another region and sometimes disappeared from the measurement at a different concentration. The ${ }^{1} \mathrm{H}$ signals at 5.45 p.p.m. ( $\mathrm{m}, \mathrm{H}-\mathrm{i}, 3.439 \mathrm{H}$ ) are related to the cis-olefin protons of the triene, diene and monoene moieties. The degree of unsaturation $(x)$ of $\mathrm{CD}$ is calculated to be 2.14 from the equation, $x=3.439 \mathrm{H} /$ $2 \mathrm{H}+0.833 \mathrm{H} / 2 \mathrm{H}$. Also, the following equation (1) is obtained from the equations, $x=3 f_{3}+2 f_{2}+f_{1}$ and $f_{3}=0.417$ :

$$
2 f_{2}+f_{1}=0.889 \text {. }
$$

The ${ }^{1} \mathrm{H}$ signals of allylic position $(\mathrm{H}-h)$ of the triene, diene and monoene moieties were observed at 2.16 p.p.m. (bs, $3.372 \mathrm{H}$ ), whose proton number is expressed by $2 f_{3}+4 f_{2}+4 f_{1}$. Therefore, the following equation is derived:

$$
f_{2}+f_{1}=0.635 \text {. }
$$

From Equations (1) and (2), $f_{2}$ and $f_{1}$ are calculated to be 0.254 and 0.381 , respectively. The ${ }^{1} \mathrm{H}$ signals of terminal methyl groups for the diene, monoene and pentadecyl moieties are observed at 0.98 p.p.m. (bm, $1.879 \mathrm{H}$ ), whose proton number is expressed by $3 f_{2}+3 f_{1}+3 f_{0}$. Although $f_{0}$ is calculated to be -0.009 from Equation (3), it is 
estimated to be 0 after considering the error of this analysis.

$$
1.879=3 f_{0}+3 f_{1}+3 f_{0}=3 \times 0.254+3 \times 0.381+3 f_{0}
$$

Therefore, $\left(f_{3}+f_{2}+f_{1}+f_{0}\right)$ is calculated to be 1.052 in this ${ }^{1} \mathrm{H}$ NMR analysis. However, it should be 1 , the values of $f_{3}, f_{2}, f_{1}$ and $f_{0}$ are compensated to be $0.397,0.241,0.362$ and 0 , respectively, after considering the error of this analysis. Their values are fairly in good agreement with the reported values $(0.41,0.22,0.34$ and 0.02 ) measured by chromatography. ${ }^{18}$

$\mathrm{CDN}$ was synthesized as a brown viscose liquid by the reaction of $\mathrm{CD}$ and paraformaldehyde in the presence of oxalic acid at the feed molar ratio of $\mathrm{CD} / \mathrm{CH}_{2} \mathrm{O}$ 1.65/1. Theoretical number of phenolic units $(p)$ is 2.54 based on the equation, $p /(p-1)=1.65$ for the addition-condensation reaction. Figure $2 \mathrm{~b}$ shows the ${ }^{1} \mathrm{H}-\mathrm{NMR}$ spectrum of $\mathrm{CDN}$ in $\mathrm{CDCl}_{3}$. Benzylic methylene protons $\left(\mathrm{Ph}-\mathrm{CH}_{2}-\right.$ $\mathrm{Ph})$ and aromatic protons $(\mathrm{Ar}-H)$ were observed at 3.88 p.p.m. (m) and 7.2-6.6 p.p.m. (m), respectively. In this case, phenolic hydroxy protons were not observed. From the ratio of $\left[\mathrm{Ph}-\mathrm{CH}_{2}-\mathrm{Ph}\right] /$ $[\mathrm{Ar}-H]=(2 p-2) /(2 p+2)=0.4326, p$ is calculated to be 2.52 , which is in good agreement with the theoretical value (2.54). As the number of unsaturated carbon chains of $\mathrm{CDN}$ is more than two, crosslinked structure can be formed even if the CD unit reacts with maleimide unit of BMI at the ratio of $1 / 1$. In the case of the reaction of $C D$ and $\mathrm{BMI}$, the polymer network would not be formed if the stoichiometric ratio of maleimide/CD was $1 / 1$.

\section{Model reaction of $\mathrm{CD}$ and $\mathrm{PMI}$}

The model reactions of CD/PMI with molar ratios of 1/2, 1/4 and 1/6 at $200^{\circ} \mathrm{C}$ for $8 \mathrm{~h}$ were carried out to elucidate the curing mechanism of $\mathrm{CCD} / \mathrm{BMI}$ or $\mathrm{CCDN} / \mathrm{BMI}$. Figure 3 shows the ${ }^{1} \mathrm{H}-\mathrm{NMR}$ spectra of cCD/PMI $1 / 2$ and $\mathrm{cCD} / \mathrm{PMI} 1 / 6$ in $\mathrm{CDCl}_{3}$. The olefinic protons of
PMI at 6.85 p.p.m. (s) completely disappeared for cCD/PMI 1/2, and new ${ }^{1} \mathrm{H}$ signals were observed at the regions of 6.2-5.2 p.p.m. $(\mathrm{H}-k)$ and 3.7-2.7 p.p.m. (H-j). The former proton signals are reasonably assigned to olefinic protons, and the latter ones to methylene or methine protons adjacent to carbonyl or vinyl groups. The ${ }^{1} \mathrm{H}$ signals due to the original cis-olefin moiety $(\mathrm{H}-i)$ decreased with increasing amount of PMI. In the case of CD/PMI $1 / 6$, the facts that the ${ }^{1} \mathrm{H}$ signals $(\mathrm{H}-\mathrm{i})$ was very weak and that broad aliphatic ${ }^{1} \mathrm{H}$ signals appeared at lower than 3.7 p.p.m. increased as is shown in Figure 3b, indicating the occurrence of addition copolymerization of the original cis-olefin moieties and PMI. Also, the appearance of broad ${ }^{1} \mathrm{H}$ signals around 4 p.p.m. suggests the occurrence of homopolymerization of PMI. ${ }^{27}$ However, the fact that the olefinic proton signal of maleimide moieties is observed at 6.85 p.p.m. for $\mathrm{cCD} / \mathrm{PMI} 1 / 6$ indicates that excess PMI remains at the reaction temperature of $200^{\circ} \mathrm{C}$. The probable reaction mechanism of $\mathrm{CD}$ and $\mathrm{PMI}$ elucidated from the ${ }^{1} \mathrm{H}-\mathrm{NMR}$ is shown in Figure 4. Thus, the ene reaction of the terminal allyl group of the pentadeca-8,11,14-triene moiety and PMI generates the cis, cis, trans-pentadeca-8,11,13-triene moiety (Equation (4)). Subsequently, the formed conjugated diene moiety undergoes a DielsAlder reaction with PMI to produce cyclohexene moiety (Equation (5)). When the trans-olefin generated by the ene reaction of isolated cis-olefin and PMI is not conjugated with another cis-olefin, the subsequent Diels-Alder reaction does not occur (Equation (6)). It is also considered that addition copolymerization of the olefins originated from $\mathrm{CD}$ and PMI and the homopolymerization of PMI occur in addition to the ene and Diels-Alder reactions.

The FTIR spectra of the model reaction products were analyzed to verify the reaction mechanism elucidated by ${ }^{1} \mathrm{H}-\mathrm{NMR}$ for $\mathrm{CCD} / \mathrm{PMI}$ (Figure 5). The analysis of the $\mathrm{C}-\mathrm{H}$ out-of-plane bending absorptions of alkenes is effective to identify their substitution manner and cis- a

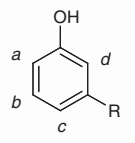

CD
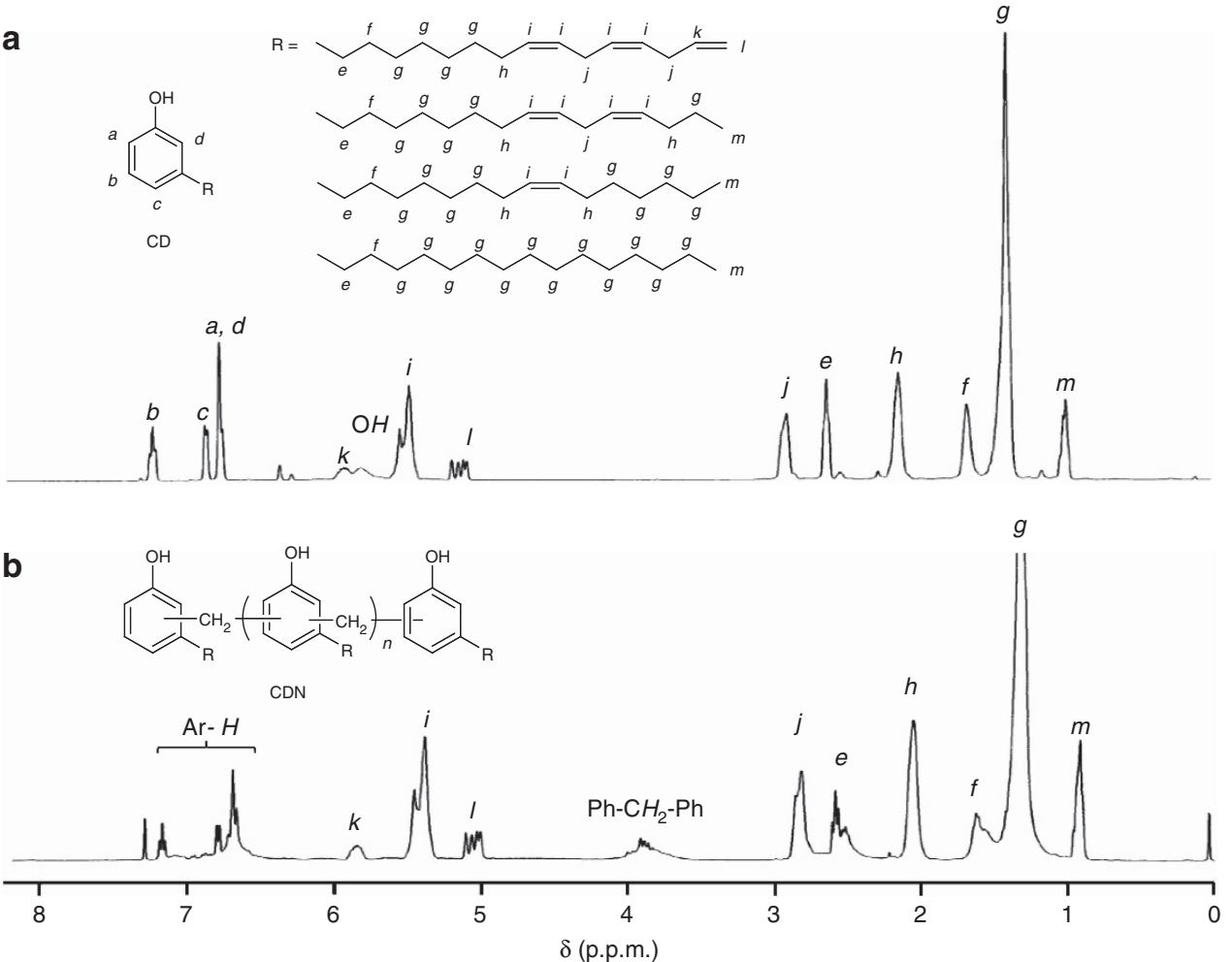

Figure 2 Proton nuclear magnetic resonance $\left({ }^{1} \mathrm{H}-\mathrm{NMR}\right)$ spectra of (a) cardanol (CD) and (b) cardanol novolac (CDN) in $\mathrm{CDCl}_{3}$. 
a
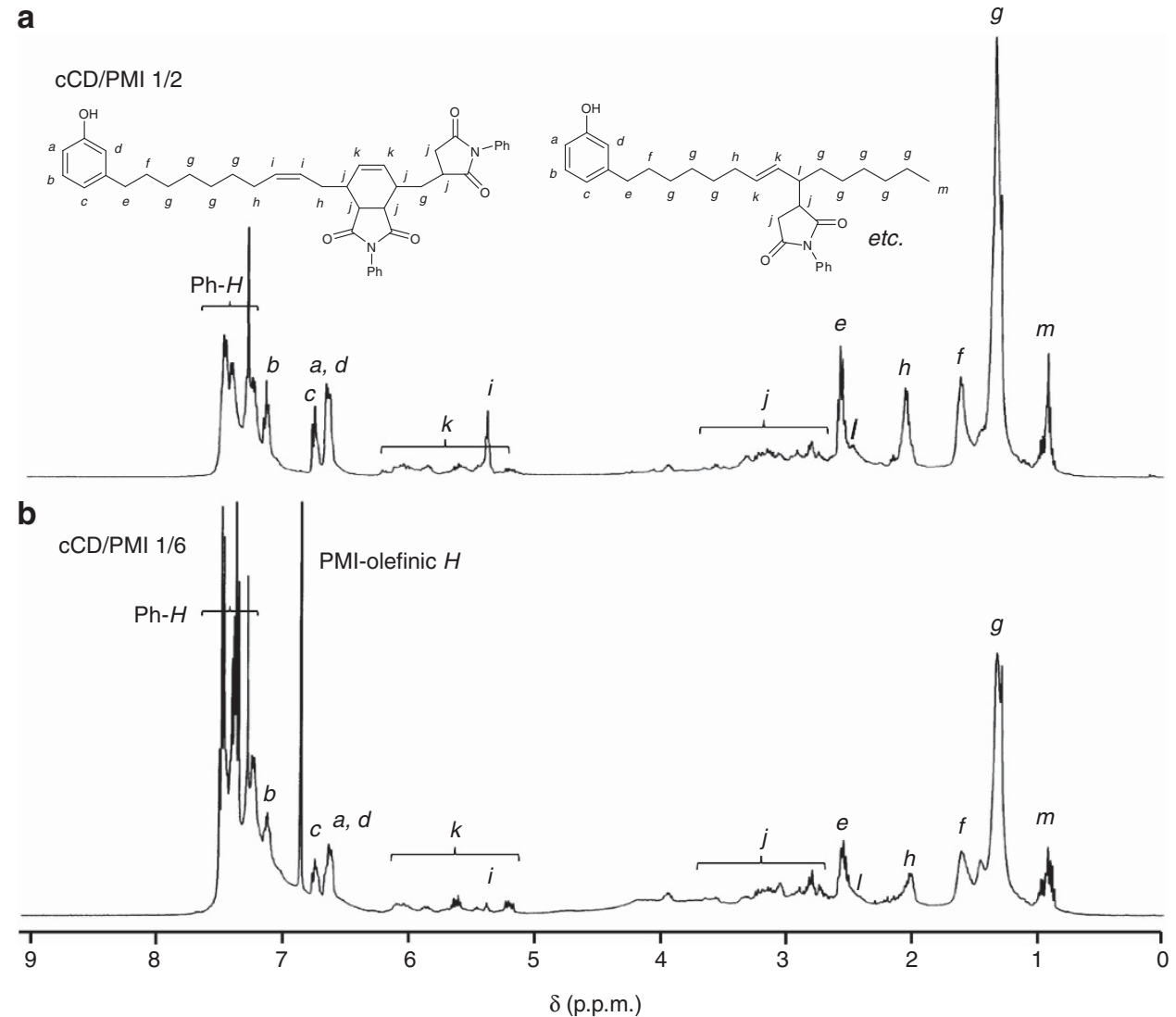

Figure 3 Proton nuclear magnetic resonance $\left({ }^{1} \mathrm{H}-\mathrm{NMR}\right)$ spectra of (a) cured cardanol (cCD)/ $\mathrm{N}$-phenylmaleimide (PMI) $1 / 2$ and (b) cCD/PMI $1 / 6$ in $\mathrm{CDCl}$.<smiles>[2H]C/C=C\C/C=C\C1C=CC2=C(C1)C(=O)N(c1ccccc1)C2=O</smiles><smiles>O=C1CC(C/C=C/C=C\C/C=C\CP)C(=O)N1c1ccccc1</smiles>

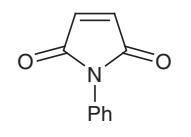<smiles>[2H]C/C=C/Cc1ccc(CC2CC(=O)N(c3ccccc3)C2=O)c2c1C(=O)N(c1ccccc1)C2=O</smiles><smiles>CCCCCCC1=CC(C)CN2C(=O)C3=C(C2=O)N(c2ccccc2)C(=O)C13</smiles><smiles>[2H]C=CC(CCCCCC)C1CC(=O)N(c2ccccc2)C1=O</smiles>

Figure 4 Probable reaction mechanism of cardanol (CD) and $\mathrm{N}$-phenylmaleimide (PMI).

trans isomerism. For example, it is known that cis-disubstituted $\mathrm{RHC}=\mathrm{CHR}$ and trans-disubstituted $\mathrm{RHC}=\mathrm{CRH}$ show the absorption peaks at $730-665 \mathrm{~cm}^{-1}$ (strong) and $980-960 \mathrm{~cm}^{-1}$ (strong), respectively. ${ }^{28}$ It is also known that vinyl $\mathrm{RHC}=\mathrm{CH}_{2}$ shows the absorption peaks at $995-985 \mathrm{~cm}^{-1}$ (strong) and $915-905 \mathrm{~cm}^{-1}$ (strong). ${ }^{29}$ The $\mathrm{C}-\mathrm{H}$ out-of-plane bending absorption peak of cisdisubstituted $\mathrm{RHC}=\mathrm{CHR}$ for $\mathrm{CD}$ was observed at $719 \mathrm{~cm}^{-1}$. Also, the C-H out-of-plane bending absorption peaks of the terminal vinyl 


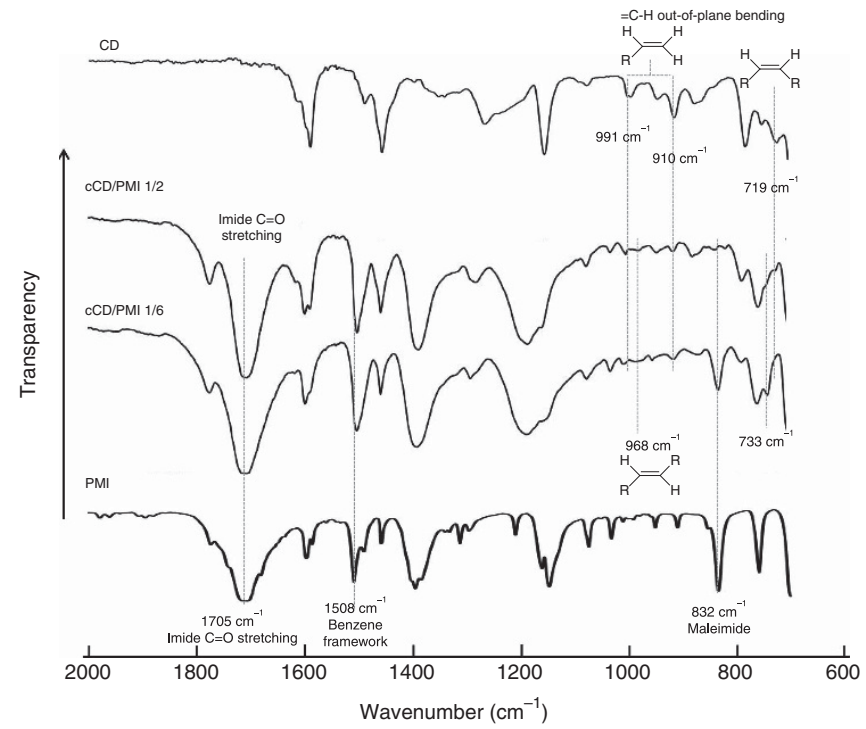

Figure 5 Fourier transform infrared (FTIR) spectra of cardanol (CD), cured $\mathrm{CD}$ (cCD)/N-phenylmaleimide (PMI) 1/2, cCD/PMI 1/6 and PMI.
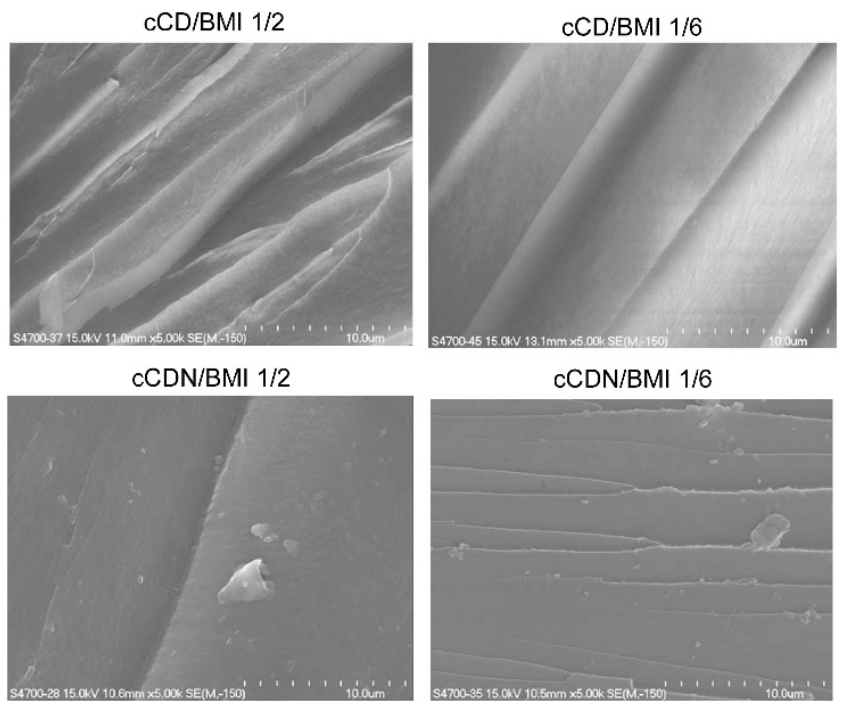

Figure 6 Field emission-scanning electron microscopy (FE-SEM) images of the fractured surfaces of cured cardanol (CCD) $/ 4,4^{\prime}$-bismaleimidediphenylmethane (BMI) and cured CD novolac (cCDN)/BMI resins. group for CD were observed at 991 and $910 \mathrm{~cm}^{-1}$. In the FTIR spectra of $\mathrm{cCD} / \mathrm{PMI} 1 / 2$ and $\mathrm{CCD} / \mathrm{PMI} 1 / 6$, the absorption peaks related to cis- $\mathrm{RHC}=\mathrm{CHR}$ and vinyl $\mathrm{RHC}=\mathrm{CH}_{2}$ observed for $\mathrm{CD}$ considerably diminished, and new absorption peaks around $968 \mathrm{~cm}^{-1}$ related to the trans $-\mathrm{RHC}=\mathrm{CRH}$ unit formed by the ene reaction appeared. Also, another new absorption peak at $733 \mathrm{~cm}^{-1}$ related to cis-RHC $=\mathrm{CHR}$ of the cyclohexene moiety formed by the ene reaction and subsequent Diels-Alder reaction. Although the absorption peak at $832 \mathrm{~cm}^{-1}$ related maleimide group disappeared for $\mathrm{CCD} /$ PMI $1 / 2$, this peak was observed for cCD/PMI $1 / 6$. The result obtained from the FTIR analysis is in good agreement with that elucidated from the ${ }^{1} \mathrm{H}-\mathrm{NMR}$ analysis.

\section{Curing reactions of $\mathrm{CD} / \mathrm{BMI}$ and $\mathrm{CDN} / \mathrm{BMI}$}

The mixture of $\mathrm{CD}$ and $\mathrm{BMI}$ with the unit ratio of $\mathrm{CD} /$ maleimide $1 / 2-1 / 6$ gelled during the prepolymerization at $200{ }^{\circ} \mathrm{C}$ for $4 \mathrm{~h}$, indicating the progress of crosslinking reaction. Similarly, the mixture of $\mathrm{CDN}$ and BMI gelled during the prepolymerization at $200^{\circ} \mathrm{C}$ for $0.5 \mathrm{~h}$. The obtained compounds of CD/BMI and CDN/BMI were compression-molded finally at $250{ }^{\circ} \mathrm{C}$ for $5 \mathrm{~h}$. Figure 6 shows FE-SEM images of the fractured surface of cCD/BMIs and cCDN/BMIs. All the cured resins of $\mathrm{CD} / \mathrm{BMI}$ and $\mathrm{CDN} / \mathrm{BMI}$ did not show any phase separation, indicating that $\mathrm{CD}$ and $\mathrm{CDN}$ copolymerized with BMI. To verify the curing mechanism estimated from the model reaction, FTIR analysis of $\mathrm{cCDN} / \mathrm{BMI}$ was performed. Figure 7 shows the FTIR spectra of CDN, cCDN/BMI $1 / 2$, cCDN/BMI $1 / 6$ and BMI over the range between 2000 and $700 \mathrm{~cm}^{-1}$. The $\mathrm{C}-\mathrm{H}$ out-of-plane bending absorption peak of cis-disubstituted $\mathrm{RHC}=\mathrm{CHR}$ was observed at $719 \mathrm{~cm}^{-1}$ for CDN in a manner similar to CD. Also, the C-H out-ofplane bending absorption peaks of terminal vinyl group for CDN were observed at 991 and $910 \mathrm{~cm}^{-1}$. The absorption peaks related to the $c i s-\mathrm{RHC}=\mathrm{CHR}$ and vinyl $\mathrm{RHC}=\mathrm{CH}_{2}$ observed for CDN almost disappeared for $\mathrm{CCDN} / \mathrm{BMI} 1 / 2$ and $\mathrm{CCDN} / \mathrm{BMI} 1 / 6$ and new broad absorption peaks around $960-980 \mathrm{~cm}^{-1}$ related to trans $-\mathrm{RHC}=\mathrm{CRH}$ were observed, indicating the occurrence of the ene reaction. Although the absorption peak related to the cyclohexene moiety generated by the Diels-Alder reaction was clearly observed at $733 \mathrm{~cm}^{-1}$ for $\mathrm{cCD} / \mathrm{PMI}$, the peak at a near wavenumber region $\left(738 \mathrm{~cm}^{-1}\right)$ was very weak for CCDN/BMI $1 / 2$ and CCDN/BMI $1 / 6$. There is a possibility that retro-Diels-Alder reaction and subsequent addition copolymerization occurred at the curing temperature of $250{ }^{\circ} \mathrm{C}$, or that Diels-Alder reaction itself is prevented by a steric hindrance by use of BMI instead of PMI and the olefinic moieties of $\mathrm{CDN}$ directly copolymerized with BMI. Figure 8 shows the comparison of FTIR spectra of CD/PMI $1 / 4$ and CDN/BMI $1 / 4$ prepolymerized at $200{ }^{\circ} \mathrm{C}$ for $8 \mathrm{~h}$. In contrast to the fact that the prepolymerized $\mathrm{CD} / \mathrm{PMI}$ showed a clear peak at $733 \mathrm{~cm}^{-1}$ based on a cyclohexene moiety, the prepolymerized CDN/BMI showed no absorption peak at a similar wavenumber region, except for the peaks based on the unreacted BMI. A similar trend was observed for CDN/BMI $1 / 2$ and CDN/BMI $1 / 4$ prepolymerized at $200{ }^{\circ} \mathrm{C}$ for $8 \mathrm{~h}$. These results strongly support that the Diels-Alder reaction is highly hindered in the case of the reaction of CDN and BMI. Although we did not show the FTIR spectra of $\mathrm{CCD} / \mathrm{BMI} 1 / 2$ and $\mathrm{CCD} / \mathrm{BMI} 1 / 6$, their spectra were very similar to those of $\mathrm{CCDN} / \mathrm{BMI} 1 / 2$ and $\mathrm{CCDN} / \mathrm{BMI} 1 / 6$, respectively, indicating that the ene reaction and addition copolymerization similarly occurred for cCD/BMIs. Regarding the effect of steric hindrance on Diels-Alder reaction, it is reported that the DielsAlder reaction did not occur but the ene reaction and subsequent addition copolymerization occurred in the reaction of DABA/PMI or DABA/BMI, whereas the model reaction of 2-allylphenol and PMI produced the ene and subsequent Diels-Alder adducts. ${ }^{14,15,29}$

\section{Thermal and mechanical properties of $\mathrm{cCD} / \mathrm{BMI}$ and $\mathrm{cCDN} / \mathrm{BMI}$}

Figures 9 and 10 show dynamic mechanical analysis curves of $\mathrm{cCD} /$ BMIs and cCDN/BMIs cured at $250^{\circ} \mathrm{C}$, respectively. The cCD/BMI $1 /$ 2 and $\mathrm{cCDN} / \mathrm{BMI} 1 / 2$ showed clear $\tan \delta$ peak temperature corresponding to glass transition temperature $\left(T_{\mathrm{g}}\right)$ at 141.7 and $158.0^{\circ} \mathrm{C}$, respectively. The storage modulus $\left(E^{\prime}\right)$ for $\mathrm{CCD} / \mathrm{BMI} 1 / 2$ and $\mathrm{cCDN} /$ BMI $1 / 2$ considerably dropped at around the $T_{\mathrm{g}}$. However, clear glass transition and decline of $E^{\prime}$ were not identified until $300-350{ }^{\circ} \mathrm{C}$ for the cured resins with a higher BMI content than $\mathrm{CCD} / \mathrm{BMI} 1 / 2$ and 


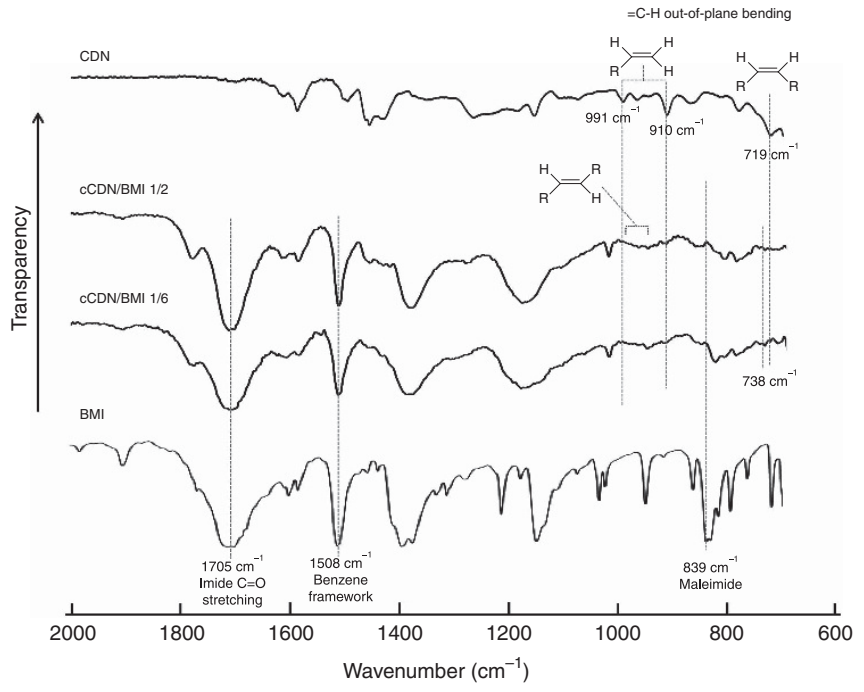

Figure 7 Fourier transform infrared (FTIR) spectra of cardanol novolac $(\mathrm{CDN})$, cured $\mathrm{CDN}$ (cCDN)/4,4'-bismaleimidediphenylmethane (BMI) 1/2, CCDN/BMI $1 / 6$ and BMI.

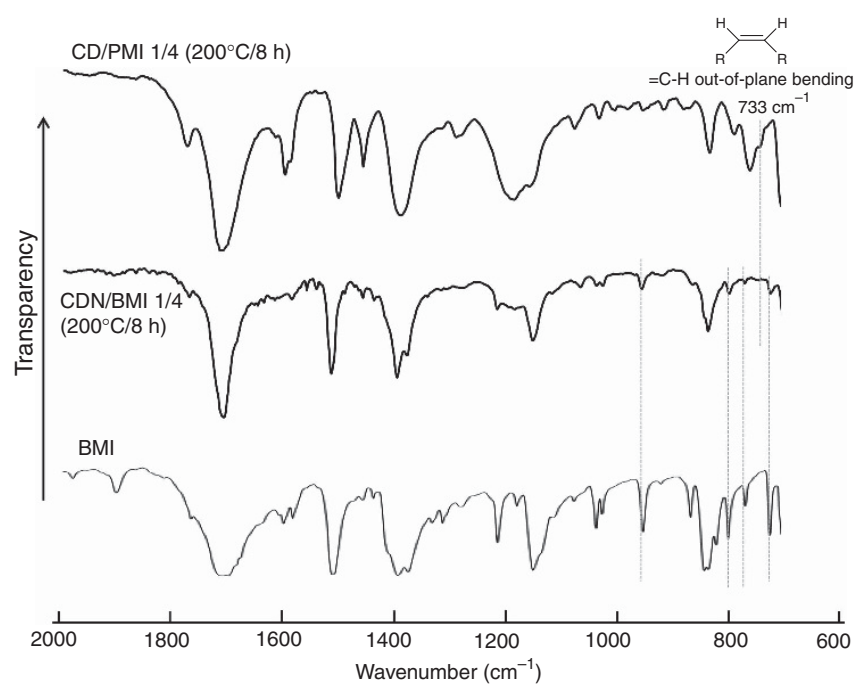

Figure 8 Fourier transform infrared (FTIR) spectra of the compounds of cardanol (CD)/ $/$-phenylmaleimide (PMI) $1 / 4$ and CD novolac (CDN)/4, $4^{\prime}$ bismaleimidediphenylmethane (BMI) $1 / 4$ prepolymerized at $200^{\circ} \mathrm{C}$ for $8 \mathrm{~h}$ and BMI.

cCDN/BMI 1/2, indicating highly crosslinked maleimide resins with superior heat resistance are obtained.

Figure 11 shows thermogravimetric analysis curves of cCD/BMI and $\mathrm{cCDN} / \mathrm{BMI}$ cured resins. The $5 \%$ weight loss temperature increased with increasing BMI content, and all the cured resins except cCD/BMI $1 / 2$ showed an excellent $5 \%$ weight loss temperature higher than $450{ }^{\circ} \mathrm{C}$. When the cured resins with the same unit ratio of $\mathrm{CD} /$ maleimide are compared, cCDN/BMI had a higher 5\% weight loss temperature than $\mathrm{CCD} / \mathrm{BMI}$ did.

Figure 12 shows flexural properties of $\mathrm{CCD} / \mathrm{BMIs}$ and cCDN/BMIs. There were little differences in flexural strength and modulus between the $\mathrm{cCD} / \mathrm{BMI}$ and $\mathrm{cCDN} / \mathrm{BMI}$ with the same unit ratio, suggesting that polymer network is formed for both the cured resins by the reaction at the stoichiometric ratio of maleimide/CD more than two. When the unit ratio is $1 / 4$, the highest flexural strength and modulus
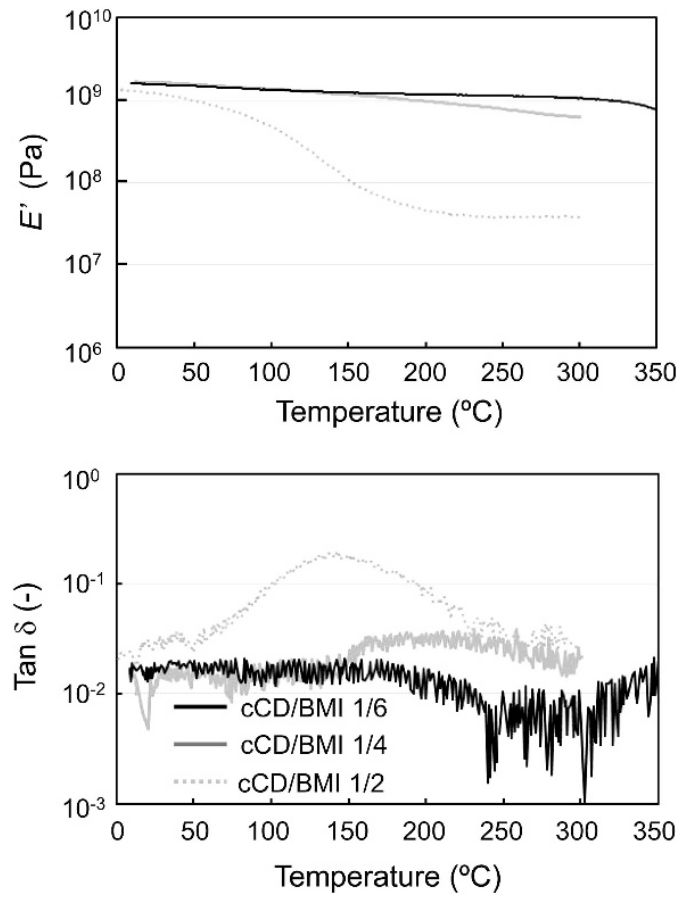

Figure 9 Dynamic mechanical analysis (DMA) curves of cured cardanol (CCD)/4,4'-bismaleimidediphenylmethane (BMI) 1/2, CCD/BMI 1/4 and CCD/ BMI $1 / 6$.
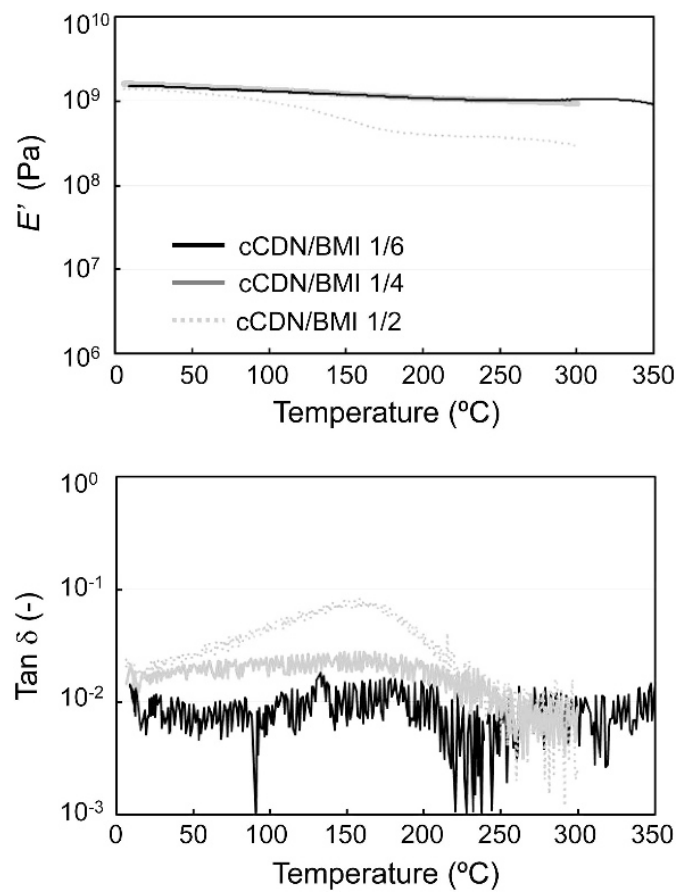

Figure 10 Dynamic mechanical analysis (DMA) curves of cured cardanol novolac (cCDN)/4,4'-bismaleimidediphenylmethane (BMI) 1/2, cCDN/BMI $1 / 4$ and CCDN/BMI $1 / 6$. 

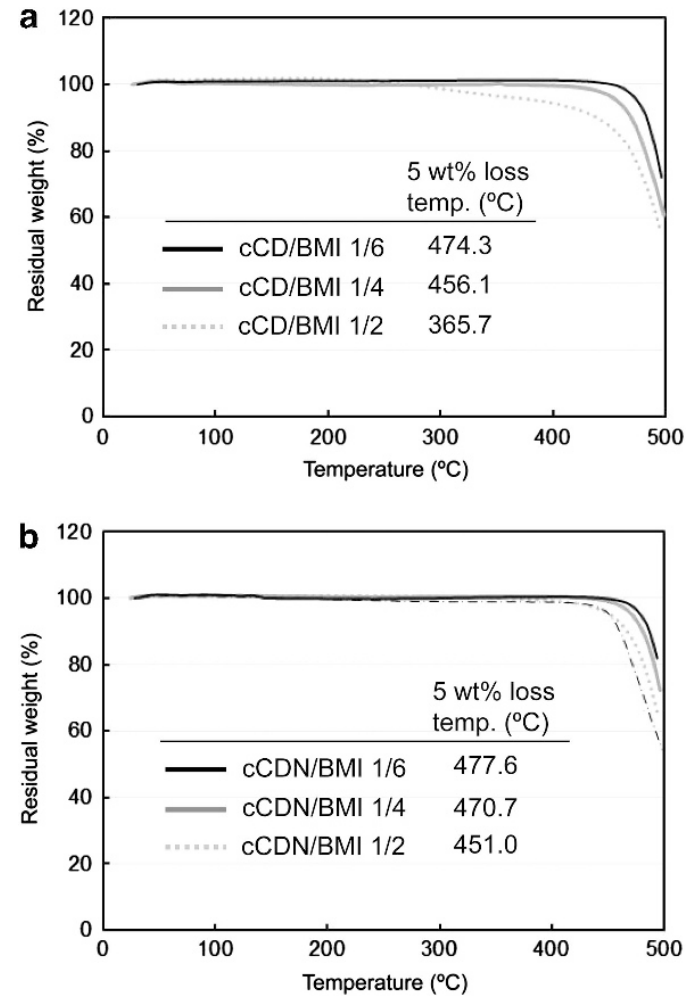

Figure 11 Thermogravimetric analysis (TGA) curves of (a) cured cardanol (CCD)/4,4'-bismaleimidediphenylmethane (BMI) and (b) cured CD novolac $(\mathrm{CCDN}) / \mathrm{BMI}$ resins.
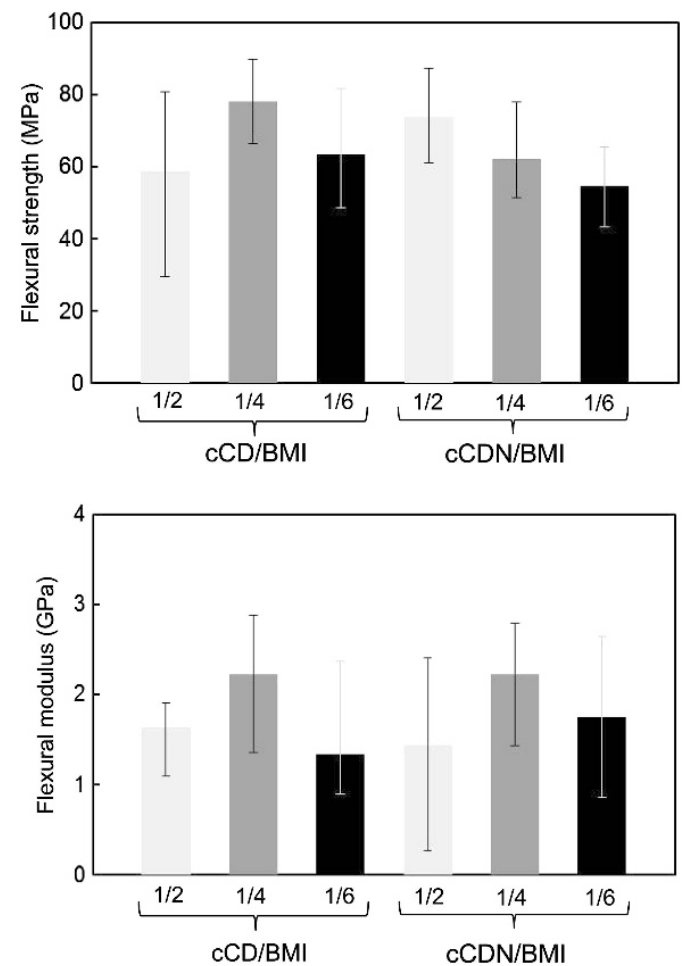

Figure 12 Flexural properties of cured cardanol (CCD)/4,4'-bismaleimidediphenylmethane (BMI) and cured CD novolac (cCDN)/BMI resins. were attained for both the resin systems, except that cCDN/BMI $1 / 4$ showed a lower flexural strength than cCDN/BMI 1/2 did. These results suggest that the introduction of a succinimide moiety with a higher fraction during the addition copolymerization contributes to the improvement of the thermal and flexural properties. The fact that flexural strength and modulus of cCD/BMI 1/6 and cCDN/BMI 1/6 were lower than those of the corresponding $1 / 4$ samples may be attributed to the brittle character of homopolymerized BMI component and/or some delamination between succinimide-rich and -poor components. Regarding the comparison with already developed petroleum-based bismaleimide resins, the flexural strength and modulus (78.0 $\mathrm{MPa}$ and $2.22 \mathrm{GPa}$ ) of $\mathrm{cCD} / \mathrm{BMI} 1 / 4$ were lower than the reported values $(172 \mathrm{MPa}$ and $4.21 \mathrm{GPa})$ of cured DABA/BMI with the molar ratio of $1 / 1$ cured at $250{ }^{\circ} \mathrm{C}$ for $6 \mathrm{~h} .{ }^{11}$ Although the occurrence of the ene reaction and vinyl copolymerzation is estimated for both the bismaleimide resin systems, the fact that the unsaturated chain $\left(C_{15}\right)$ of $C D$ is much longer than those $\left(C_{3}\right)$ of DABA should be attributed to the difference of the flexural properties.

\section{CONCLUSIONS}

CDN ( $p=2.52)$ was synthesized by the reaction of CD $(x=2.14)$ and paraformaldehyde. The prepolymerized compounds of CDN/BMI and $\mathrm{CD} / \mathrm{BMI}$ with $\mathrm{CD} /$ maleimide ratios $1 / 2,1 / 4$ and $1 / 6$ at $200^{\circ} \mathrm{C}$ were finally compression-molded at $250^{\circ} \mathrm{C}$ for $5 \mathrm{~h}$ to produce cCDN/ $\mathrm{BMI}$ and $\mathrm{CCD} / \mathrm{BMI}$, respectively. The FE-SEM analysis revealed that homogeneous cured resins without phase separation were obtained for cCD/BMI and cCDN/BMI. Although the ${ }^{1} \mathrm{H}-\mathrm{NMR}$ and FTIR analyses of the model reaction product of $\mathrm{CD}$ and PMI at $200{ }^{\circ} \mathrm{C}$ for $8 \mathrm{~h}$ suggested the occurrence of the ene reaction and subsequent Diels-Alder reaction, the FTIR analysis of $\mathrm{cCD} / \mathrm{BMI}$ and $\mathrm{cCDN} / \mathrm{BMI}$ suggested the occurrence of the ene reaction and addition copolymerization. The $\mathrm{cCDN} / \mathrm{BMI}$ and $\mathrm{cCD} / \mathrm{BMI}$ with $\mathrm{CD} /$ maleimide ratio lower than $1 / 2$ did not show glass transition until $300{ }^{\circ} \mathrm{C}$ and had a $5 \%$ weight loss temperature higher than $450{ }^{\circ} \mathrm{C}$. The cCDN/BMI and cCD/BMI with $\mathrm{CD} /$ maleimide ratio $1 / 4$ showed the most balanced flexural properties (flexural strength $60-80 \mathrm{MPa}$, flexural modulus $2.0-2.5 \mathrm{GPa})$.

\section{CONFLICT OF INTEREST}

The authors declare no conflict of interest.

\section{ACKNOWLEDGEMENTS}

We thank Dr Naozumi Teramoto of our department for the helpful suggestions and measuring ${ }^{1} \mathrm{H}-\mathrm{NMR}$ spectra. We are also grateful to Mr Ryusuke Osada of Material Analysis Center of our university for assisting in FE-SEM measurements.

1 Sun, X. S. in Bio-Based Polymers and Composites (eds Wool, R. P. \& Sun, X. S.) Ch. 1 1-14 (Elsevier, New York, 2005).

2 Kaplan, D. L. in Biopolymers from Renewable Resources (ed. Kaplan, D. L.) Ch.1, 1-29 (Springer, Berlin, 1998).

3 Yu, L., Petinakis, S., Dean, K., Bilyk, A. \& Wu, D. Green polymeric blends and composites from renewable resources. Macromol. Symp. 249/250, 535-539 (2007).

4 Yu, L., Dean, K. \& Li, L. Polymer blends and composites from renewable resources. Prog. Polym. Sci. 31, 576-602 (2006).

5 Ronda, J. C., Lligadas, G., Galià, M. \& Cádiz, V. A renewable approach to thermosetting resins. React. Funct. Polym. (advance online publication 24/2012).

$6 \mathrm{Kim}$, J. R. \& Sharma, S. The development and comparison of bio-thermoset plastics from epoxidized plant oils. Ind. Crop. Prod. 36, 485-499 (2012).

7 Raquez, J. M., Deléglise, M., Lacrampe, M. F. \& Krawczak, P. Thermosetting (Bio)materials derived from renewable resources: a critical review. Prog. Polym. Sci. 35, 487-509 (2010). 
8 Effendi, A., Gerhauser, H. \& Bridgwater, A. V. Production of renewable phenolic resins by thermochemical conversion of biomass: a review. Renew. Sustain. Energy Rev. 12, 2092-2116 (2008).

9 Wool, R. P. in Bio-Based Polymers and Composites (eds. Wool, R. P. \& Sun, X. S.) Ch 7, 202-255 (Elsevier, New York, 2005).

10 Nair, C. P. R. Advances in addition-cure phenolic resins. Prog. Polym. Sci. 29, 401-498 (2004).

11 Hopewell, J. L., George, G. A. \& Hill, D. J. T. Quantitative analysis of bismaleimide-diamine thermosets using near infrared spectroscopy. Polymer (Guildf) 41, 8221-8229 (2000).

12 Chaplin, A., Hamerton, I., Herman, H., Mudhar, A. K. \& Shaw, S. J. Studying water uptake effect in resins based on cyanate ester/bismalemide blends. Polymer (Guildf) 41, 3945-3956 (2000).

13 King, J. J., Chaudhari, M. \& Zahir, S. A new bismaleimide system for high performance applications. 29th SAMPE Symposium 29, 392-403 (1984).

14 Morgan, R. J., Shin, E. E., Rosenberg, B. \& Jurek, A. Characterization of the cure reactions of bismaleimide composite matrices. Polymer (Guildf) 38, 639-646 (1997).

15 Rozenberg, B. A., Dzhavadyan, E. A., Morgan, R. \& Shin, E. High-performance bismaleimide matrices: cure kinetics and mechanism. Polym. Adv. Technol. 13, 837-844 (2002).

16 Hirayama, K., Irie, T., Teramoto, N. \& Shibata, M. High performance bio-based thermosetting resins composed of dehydrated castor oil and bismaleimide. J. Appl. Polym. Sci. 114, 1033-1039 (2009).

17 Shibata, M., Teramoto, N. \& Nakamura, Y. High performance bio-based thermosetting resins composed of tung oil and bismaleimide. J. Appl. Polym. Sci. 119, 896-901 (2011).

18 Chiellini, E., Chiellini, F. \& Cinelli, P. in Degradable Polymers: Principles and Applications (ed. Scott, G.) Ch. 7, 192-194 (Springer, Berlin, 2003).

19 Roy, D. R., Basu, P. K., Raghunathan, P. \& Eswaran, S. V. Cashew nut shell liquid-based tailor-made novolac resins: polymer morphology quantitatation by 1-D and 2-D NMR techniques and performance evaluation. J. Appl. Polym. Sci. 89, 1959-1965 (2003).
20 Yadav, R., Devi, A., Tripathi, G. \& Srivastava, D. Optimization of the process variables for the synthesis of cardanol-based novolac-type phenolic resin using response surface methodology. Eur. Polym. J. 43, 3531-3537 (2007).

21 Santos, R. S. S., Souza, A. A., Paoli, M. A. \& Souza, C. M. L. Cardanol-formaldehyde thermoset composites reinforced with buriti fibers: preparation and characterization. Composites Part A 41, 1123-1129 (2010).

22 Devi, A. \& Srivastava, D. Studies on the blends of cardanol-based epoxidized novolac type phenolic resin and carboxyl-terminated polybutadiene (CTPB), I. Mater. Sci. Eng. A 458, 336-347 (2007).

23 Kim, Y. H., An, E. S., Park, S. Y. \& Song, B. K. Enzymatic epoxidation and polymerization of cardanol obtained from a renewable resource and curing of epoxide-containing polycardanol. J. Mol. Catal. B 45, 39-44 (2007).

24 Campaner, P., D'Amico, D., Longo, L., Stifani, C. \& Tarzia, A. Cardanolbased novolac resins as curing agents of epoxy resins. J. Appl. Polym. Sci. 114, 3585-3591 (2009).

25 Yadav, R. \& Srivastava, D. Synthesis and properties of cardanol-based epoxidized novolac resins modified with carboxyl-terminated butadiene-acrrylonitrile copolymer. J. Appl. Polym. Sci. 114, 1670-1681 (2009).

26 Bai, W., Xiao, X., Chen, Q., Xu, Y., Zheng, S. \& Lin, J. Synthesis and characterization of cross-linked polymer from cardanol by solvent-free grinding polymerization. Prog. Org. Coat. 75, 184-189 (2012)

27 Lu, Y., Sun, W. \& Shen, Z. Polymerization of $N$-phenylmaleimide with a rare-earth coordination catalyst. J. Appl. Polym. Sci. 96, 979-982 (2005).

28 Silverstein, R. M., Webster, F. X. \& Kiemle, D. J. Spectrometric Identification of Organic Compounds. 7th edn, Vol. 125 (Wiley, Hoboken, 2005).

29 Shibahara, S., Yamamoto, T., Yamaji, T., Motoyoshiya, J. \& Hayashi, S. Thermal reactions of $\mathrm{N}$-phenylmaleimide and mono- or di-functional allylphenols. Polym. J. 30, 404-409 (1998). 